\title{
Global Health: Role of HPV Testing in Resource Poor Environment
}

\section{Citation}

Goodman, A, N Joseph, LS Bradford, and BR Dey. 2015. "Global Health: Role of HPV Testing in Resource Poor Environment." Journal of Genital System \& Disorders 4, no. 4.

\section{Permanent link}

http://nrs.harvard.edu/urn-3:HUL.InstRepos:40839015

\section{Terms of Use}

This article was downloaded from Harvard University's DASH repository, and is made available under the terms and conditions applicable to Other Posted Material, as set forth at http:// nrs.harvard.edu/urn-3:HUL.InstRepos:dash.current.terms-of-use\#LAA

\section{Share Your Story}

The Harvard community has made this article openly available.

Please share how this access benefits you. Submit a story.

\section{Accessibility}




\section{Global Health: Role of HPV Testing in Resource Poor Environment}

\author{
Goodman A ${ }^{1 *}$, Joseph N11, Bradford LS ${ }^{2}$, Dey BR
}

\begin{abstract}
Eighty-five percent of cervical cancer deaths occur in the developing world. While cervical cancer is only the tenth most common cancer in women in developed countries, it is the leading cause of cancer related deaths in women in low and middleincome countries (LMICs). Despite this, there is a disproportionate allocation of cervical-cancer related resources in countries with the highest burden. Cervical cancer is preventable and amenable to early detection and treatment. Over the past two decades, largescale data investigating low cost screening interventions have demonstrated efficacy of cervical cancer prevention in many continents. Further, use of HPV vaccine alone has the potential to reduce cervical cancer deaths by $50 \%$ over several decades. Decreased overall prevalence of HPV in conjunction with the development of new testing for high risk HPV subtypes has the potential to improve the predictive ability of a single negative HPV test for up to a decade. Nonetheless, in LMICs cervical cancer remains a leading cause of cancer-related morbidity and mortality affecting women. This suggests the focus must shift towards novel and innovative techniques that are widely acceptable and will have a positive impact on access to cervical cancer screening, improved diagnosis, treatment and survival.
\end{abstract}

\section{Keywords}

Human papillomavirus; HPV; Low and middle income countries; LMIC; HPV testing; Cervical cancer screening

\section{Discussion}

There have been numerous efforts directed at improving primary and secondary prevention of cervical cancer. Clinical trials have found that HPV vaccination (Gardasil, Gardasil 9, Cerverix) is at least $95 \%$ effective in preventing HPV-16 or -18 persistent infection, and at least $93 \%$ effective in preventing vaccine-type specific lesions when given to girls prior to onset of sexual activity, or to those without prior infection with these subtypes [1-3]. The data also demonstrates that the HPV vaccine is widely accepted in LMICs. Vaccine coverage ranging from $55-75 \%$ can be achieved when delivery is school-based, health center based or combined with other health interventions [4,5]. However, widespread vaccination is not feasible due to sociocultural sensibilities, government distrust, and lack of patient anatomy and cost [6]. Secondary prevention in high-income countries with the Papanicolaou (Pap) smear has led to

${ }^{*}$ Corresponding author: Goodman A, MD, MS, Department of Obstetrics and Gynecology, Massachusetts General Hospital Boston, MA, USA, Tel: 617-7244800; E-mail: agoodman@mgh.harvard.edu

Received: November 09, 2015 Accepted: December 09, 2015 Published: December 15, 2015 dramatic reduction of cervical cancer $[7,8]$. Over $90 \%$ of women in LMICs have never had a pap smear because of a lack of infrastructure for performance and interpretation of cytology, as well as the need for skilled cytotechnologists and cytopathologists. Yet cytology can be a low cost screening tool with immediate results. Programs have been developed where slides can be processed and screened on site during a clinic [9]. The majority of screening programs, however, have abandoned cytology as an option and focused attention and resources on visual inspection methods (such as visual inspection with acetic acid (VIA)), with a "see-and-treat approach", thus eliminating the need for pathology-based intervention.

Cervical cancer screening with VIA has been an inexpensive intervention that has been used worldwide in resource poor regions. In a meta-analysis of eleven African and Indian cohort and cluster randomized trials of VIA compared to colposcopy and biopsies, VIA had a sensitivity of $79 \%$ and a specificity of $85 \%$ for the detection of CIN2 or greater [10]. A strong advantage of this technique is that it can be taught to community workers [11]. VIA can be used either as a triage to more complex screening protocols of colposcopy and biopsy or in a see-and-treat protocol [12]. In a seven-year follow-up where 60,631 women were randomized to VIA versus health education, there was a $25 \%$ decrease in cervical cancer incidence and a $35 \%$ reduction in cancer mortality in the VIA group [13].

HPV-testing, both alone and in conjunction with VIA, is an exciting area of research and development. While prevention with HPV vaccination is an important step in decreasing cervical cancer incidence and mortality, the prevalence and distribution of HPV subtypes has a geographic and ethnic variation [14]. The International Agency for Research on Cancer (IARC) HPV prevalence survey that recruits women from 26 regions for testing of HPV subtype infections identified a high prevalence of HPV in sub-Saharan Africa, Latin America, and India [15]. These regions have the highest rates of cervical cancer worldwide [16].

The specific high-risk HPV subtype varies by continent and by ethnic group. One large retrospective analysis of 8977 paraffin specimens of invasive cervical cancer from six different continents identified HR-HPV subtype by PCR analysis [17]. HPV-16 associated cancers ranged from $66 \%$ to $72 \%$ in Europe and North America, while in South America and Oceania it was 59\%, 60\% in Asia, and $48 \%$ in Africa. The greatest proportion of HPV -18 associated cervical cancers (23\%) occurred in Africa. HPV-45 was an important highrisk subtype involving $10 \%$ of cancers in Africa, and $4-7 \%$ of cancers on other continents. HPV-33 was another significant minor highrisk subtype in both North America involving 6\% of cancers and South America with $4 \%$ while it involved less than 3 percent in other continents. The remaining eight HR-HPV subtypes were associated with less than four percent of cancers. In Bhutan, $70 \%$ of cervical cancers contain HPV-16, and -18 [18].

Africa has the highest regional prevalence of HPV overall with $22 \%$ of women with HPV infections [17]. In Uganda, HPV -52 and -51 are more common than HPV -16 and -18 with detection rates of 12-13 percent versus 11 percent respectively [19]. In a study of 135 smears in Sudan, HPV 16 and 58 were the predominant HR-HPV subtypes [20]. 
An international cost-effective analysis evaluated several strategies for cervical cancer screening in Thailand, India, Peru, Kenya, and South Africa [21]. If women are screened once in their lifetime at around age 35 years with either Visual Inspection with Acetic acid (VIA) or HPV testing, a 25 to $36 \%$ reduction in lifetime risk can occur. Risk is reduced further with a $40 \%$ reduction for two screenings.

Women in rural India were randomized to HPV testing with Hybrid Capture 2 High-Risk HPV DNA Test" (HC-2) or no screening, cytological analysis, or VIA. In 8 years of follow-up, there were 34 deaths from cervical cancer in the HPV screened group as opposed to 54 deaths in the cytology group, 56 deaths in the VIA group, and 64 in the no screen group. Thus the cumulative incidence of advance cervical cancer was lower in women who had one HPV test versus no intervention [22]. Of note, the technicians responsible for processing HC-2 and reading cytology smears had had only three months of training.

In general, HPV tests are too expensive for a low resource setting. However one less expensive kit, care HPV (Qiagen Inc Gaithersberg $\mathrm{MD}$ ) costs USD $\$ 5.00$. In a study of 2388 women between the ages of 30 and 54, VIA, cytology, HPV testing with HC-2 and care HPV was performed. Colposcopy with biopsy was done as needed. The sensitivities and specificities of CIN2/3 were 41.4/94.5 for VIA, 85.3/87.5 for cytology, 97.1/85.6 for HC2, and 84.3/87.7 for care HPV [23]. In another cross sectional study of 5032 women in rural India, care HPV was superior to VIA and Pap testing for the detection of high-grade preinvasive cervical lesions [24]. An innovative digital diffraction analysis using a smartphone is being currently evaluated to detect HPV DNA and may be another low cost approach to screening [25].

IARC is creating a electronic directory of global screening programs through their IARC screening group http://screening. iarc.fr/cervicalindex.php [15]. There is also a coalition of healthcare advocacy organizations reports on cervical cancer screening efforts and disseminates lectures and pamphlets on screening in developing countries [26]. As more complete data emerges about worldwide cervical cancer rates and outcomes, HPV prevalence by region, and screening programs, it will be possible to fashion interventions of low cost screening and vaccination programs that are region and ethnic group appropriate.

\section{References}

1. Globocan. Cervical Cancer estimated Incidence, mortality, and prevalence worldwide in 2012.

2. Bradford LS, Goodman A (2013) Cervical cancer screening and prevention in low resource settings. Clin Obstet Gynecol 56: 76-87.

3. Agosti JM, Goldie SJ (2007) Introducing HPV vaccine in developing countries - key challenges and issues. N Engl J Med 356: 1908-1910.

4. Goodman A (2015) Human papillomavirus infection and cervical cancer. BMJ 350: h2372.

5. LaMontagne DS, Barge S, Le NT, Emmanuel M, Mary EP, et al. (2011) Human papillomavirus vaccine delivery strategies that achieved high coverage in low- and middle-income countries. Bull World Health Organ 89: 821-830.

6. Goodman A, Joseph, N (2015) Is Universal Implementation of Human Papillomavirus Vaccination Feasible? An Analysis of the Barriers to Primary Prevention Strategies for Cervical Cancer. Med Res Arch 2: 08-18.

7. Papanicolaou GN, Traut HF (1997) The diagnostic value of vaginal smears in carcinoma of the uterus. 1941. Arch Pathol Lab Med 121: 211-224.

8. Andrae B, Andersson TM, Lambert PC, Levent K, Lena S, et al. (2012) Screening and cervical cancer cure: population based cohort study. BMJ 344: e900.
9. Suba EJ, Nguyen $\mathrm{CH}$, Nguyen BD, Raab SS (2001) De novo establishment and cost-effectiveness of Papanicolau cytology screening services in the Socialist Republic of Vietnam. Cancer 91: 928-939.

10. Arbyn M, Ronco G, Anttila A, Meijer CJ, Poljak M, et al. (2012) Evidence regarding human papillomavirus testing in secondary prevention of cervical cancer. Vaccine 30S: F88-99.

11. Bradford LS, Dey BR, Hussain SMA, Begum RS, Hussain F, et al. (2012) Development of a cervical cancer screening program in a slum setting using visual inspection with acetic acid: Analysis of feasibility and cost. Open $J$ Obstet Gynecol 2: 140-146.

12. World Health Organization (WHO) Guidelines for Screening and treatment of precancerous lesion for Cervical Cancer prevention 2013.

13. Sankaranarayanan R, Esmy PO, Rajkumar R, Muwonge R, Swaminathan $R$, et al. (2007) Effect of visual screening on cervical cancer incidence and mortality in Tamil Nadu, India: a cluster-randomised trial. Lancet 370: 398406.

14. Natphopsuk S, Settheetham-Ishida W, Pientong C, Sinawat S, Yuenyao P et al. (2013) Human papillomavirus genotypes and cervical cancer in Northeast Thailand. Asian Pac J Cancer Prev 14: 6961-6964.

15. International Agency for Research on Cancer IARC Screening Group: Cervical Cancer.

16. Franceschi S, Herrero R, Clifford GM, Snijders PJ, Arslan A, et al. (2006) Variations in the age-specific curves of human papillomavirus prevalence in women worldwide. Int J Cancer 119: 2677-2684.

17. de Sanjosé S, Quint WGV, Alemany L, Geraets DT, Klaustermeier JE, et al. (2010) Human papillomavirus genotype attribution in invasive cervical cancer: a retrospective cross-sectional worldwide study. Lancet Oncol 11: 1048-1056

18. Tshomo U, Franceschi S, Dorji D, lacopo B, Vanessa T, et al. (2014) Human papillomavirus infection in Bhutan at the moment of implementation of a national HPV vaccination programme. BMC Infect Dis 14: 408.

19. Banura C, Francheschi S, Doorn LJ, Arslan A, Fred WM, et al. (2008) Infection with human papillomavirus and HIV among young women in Kampala, Uganda. J Infect Dis 197: 555-562.

20. Salih MM, Safi ME, Hart K, Tobi K, Adam I (2010) Genotypes of human papilloma virus in Sudanese women with cervical pathology. Infect Agent Cancer 5: 26 .

21. Goldie SJ, Gaffikin L, Goldhaber JD, Gordillo-Tobar A, Carol L, et al. (2005) Cost-Effectiveness of Cervical-Cancer Screening in Five Developing Countries. New Eng J Med 353: 2158-2168.

22. Sankaranarayanan R, Nene BM, Shastri SS, Jayant K, Muwonge R, et al. (2009) HPV Screening for Cervical Cancer in Rural India. New Eng J Med 360: 1385-1394.

23. Qiao YL, Sellors JW, Eder PS, Bao YP, Lim JM, et al. (2008) A new HPV-DNA test for cervical-cancer screening in developing regions: a cross-sectional study of clinical accuracy in rural China. Lancet Oncol 9: 929-936.

24. Labani S, Asthana S, Sodhani P, Gupta S, Bhambhani S, et al. (2014) CareHPV cervical cancer screening demonstration in a rural population of north India. Eur J Obstet Gynecol Reprod Biol 176: 75-79.

25. Im H, Castro CM, Shao H, Liong M, Song J, et al. (2015) Digital diffraction analysis enables low-cost molecular diagnostics on a smartphone. PNAS 112: $5613-5618$

26. Cervical cancer action: A Global Coalition to stop cervical cancer.

\section{Author Affiliation}

Top

${ }^{1}$ Department of Obstetrics and Gynecology, Massachusetts General Hospital Boston, MA, USA

${ }^{2}$ Department of Obstetrics and Gynecology, University of Massachusetts, Worcester, MA, USA

${ }^{3}$ Department of Medicine, Division of Hematology Oncology, Massachusetts General Hospital, USA 